\title{
ARTÍCULO
}

\section{El pragmatismo de A. M. Schweigaard: un guante nórdico contra la Filosofía idealista alemana}

\section{A. M. Schweigaard's pragmatism: a Nordic glove against German idealistic philosophy}

\author{
Guillermo Vicente y Guerrero \\ Área de Filosofía del Derecho \\ Universidad de Zaragoza
}

Fecha de recepción 31/12/2020 | De aceptación: 03/03/2021 | De publicación: 24/06/2021

\section{RESUMEN.}

A. M. Schweigaard intentó acercar el Derecho a la sociedad, liberándolo de las cadenas que le ataban a un universo conceptual sin referentes reales. Para ello procedió a la crítica de aquellos métodos que atrapaban al hecho jurídico dentro de un férreo sistema lógico, lanzando su guante en señal de reto contra las corrientes idealistas que marcaban el rumbo de la Filosofía alemana en la primera mitad del ochocientos. Su obra resultó clave para el singular rumbo pragmático, empirista y utilitarista que dirigiría ya el desarrollo futuro de la Ciencia jurídica noruega.

\section{PALABRAS CLAVE.}

Filosofía del Derecho, realismo jurídico, Anton Martin Schweigaard, pragmatismo, Noruega siglo XIX, idealismo alemán.

\section{ABSTRACT.}

A.M. Schweigaard featured the attempt of approaching the Law with the society by setting the legal framework free of the chains which linked an empty conceptual universe of real referents. In doing so, he criticized those methods that embraced the juridical fact within an airtight logic system through challenging the previous and well-known theories such as idealism. That doctrine headed the course of the German philosophy in the first half of the nineteenth century. His contributions were key for theories such as pragmatism, empiricism, and utilitarianism which were addressing the future development of the Norwegian Juridical Science.

\section{KEY WORDS.}

Philosophy of Law, legal realism, Anton Martin Schweigaard, pragmatism, Norway 19th century, German idealism. 
Sumario: 1. Introducción. 2. El "primer Schweigaard”. Notas para una biografía intelectual. 3. "Om den tyske Filosofi" ("Sobre la Filosofía alemana"). 3.1. Planteamientos generales. 3.2. Un guante contra la Filosofía germana. 3.3. La experiencia como fundamento del conocimiento. 4. Conclusión. 5. Bibliografía.

\section{Introducción ${ }^{1}$}

El realismo jurídico noruego es una corriente de pensamiento profundamente empirista, antiformalista y antimetafísica ${ }^{2}$. Conoció un notable desarrollo a partir de 1945, fecha clave para la historia de Noruega, al verse definitivamente libre dicho país nórdico de la ocupación militar llevada a cabo por la Alemania de Adolf Hitler en el transcurso de la Segunda Guerra Mundial. Desde ese momento el pequeño universo cultural noruego volvió los ojos hacia el mundo anglosajón, alejándose así de la órbita germana, desarrollando un fuerte pragmatismo que interconectaba las distintas ciencias sociales a través de una metodología de carácter empírico ${ }^{3}$.

Ese importante giro facilitó la toma en consideración del pujante realismo legal americano, del que el propio Torstein Eckhoff se convertiría en autorizado introductor con su primera gran obra: Rettsvesen og Rettsvitenskap i USA (Sobre el Derecho y la Ciencia jurídica en Estados Unidos) 4 . Paralelamente se experimentó con fuerza el influjo de la poderosa Escuela de Uppsala, con Axel Hägerstrom a la cabeza, cuyas ideas fueron aplicadas al ámbito de lo jurídico con una notable habilidad por el oscuro Vilhelm Lundstedt y por el demoledor Karl Olivecrona ${ }^{5}$, difundiéndose de forma definitiva por el danés Alf Ross, cuya principal obra, Om ret og retfærdighed (Sobre el Derecho y la Justicia) $)^{6}$, constituyó un elemento clave para la definitiva expansión de las ideas realistas ${ }^{7}$.

\footnotetext{
${ }^{1}$ La traducción al castellano de las fuentes originales noruegas y danesas utilizadas en la elaboración del presente trabajo es de mi exclusiva responsabilidad.

2 Agradezco al doctor Gert-Fredrik Malt, profesor de la Facultad de Derecho de Oslo, sus agudas sugerencias como paciente lector del manuscrito original.

${ }^{3}$ Sobre el particular: SLAGSTAD, R., "Norsk rettsrealisme etter 1945" (El realismo jurídico noruego después de 1945), Tidsskrift for Rettsvitenskap, 2/1987, pp. 385-403.

${ }^{4}$ ECKHOFF, T., Rettsvesen og Rettsvitenskap i USA (Sobre el Derecho y la Ciencia jurídica en Estados Unidos), Oslo, Akademisk Forlag, 1953.

${ }^{5}$ En castellano se cuenta con un buen trabajo sobre el particular: HIERRO, L., El realismo jurídico escandinavo. Una teoría empirista del Derecho, Valencia, Fernando Torres, 1981.

${ }^{6}$ ROSS, A., Om ret og retfcerdighed, Copenhague, Nyt nordisk forlag, 1953. Traducción al castellano: Sobre el Derecho y la Justicia, Buenos Aires, Eudeba, 1963.

${ }^{7}$ Sobre el gran maestro danés resulta muy sugerente: EVALD, Jens, Alf Ross - Et liv, Copenhague, Djøf Forlag, 2010. Traducción inglesa: Alf Ross - A life, Copenhague, Djøf Forlag, 2014.
} 
No obstante, y pese a esa señalada influencia exterior, el realismo jurídico noruego mantuvo como base su propia tradición empirista, marcada por la obra de Anton Martin Schweigaard, cuya labor fue esencial en la gestación de una Filosofía jurídica de carácter pragmático, empirista y utilitarista. Reconocido con los elogiosos calificativos de "padre de la Filosofía del Derecho noruega" y de “precursor nacional de las ideas realistas”, ejerció sobre el pequeño universo jurídico noruego un papel similar al protagonizado por el jurista Anders Sandøe Ørsted en Dinamarca ${ }^{8}$.

Este enfoque del fenómeno jurídico encontró entusiastas seguidores a lo largo del camino ${ }^{9}$, entre los que destacaron un importante número de fílósofos del Derecho de probada valía como Fredrik Stang, Ragnar Knoph o Gunnar Astrup Hoel ${ }^{10}$. Y en especial Torstein Eckhoff, sin lugar a dudas el principal jurista noruego realista. También un joven grupo de sociólogos del Derecho activos y comprometidos con la promoción de esa nueva ciencia que, encabezados por Vilhelm Aubert, se reunieron en torno al Grupo de Sociología Jurídica de Oslo, desarrollando buena parte de sus trabajos al calor del recién constituido Institutt for Samfunnsforsking (Instituto de Investigaciones Sociales) ${ }^{11}$.

\section{El "primer Schweigaard". Notas para una biografía intelectual}

A. M. Schweigaard debe encuadrarse inicialmente en un contexto histórico tan complejo como agitado, el de las guerras napoleónicas. Sus primeros años de vida coincidieron precisamente con la materialización de los pujantes sentimientos nacionalistas de Noruega que, aprovechando la renuncia del rey danés Frederik VI recogida en el Tratado de Kiel de 14 de enero de 1814, reunió entre abril y mayo en Eidsvoll una Asamblea Nacional para dotar al país de una moderna Constitución ${ }^{12}$. Dicho texto se convertiría no solo en el fundamento legal de todo el proceso revolucionario ${ }^{13}$, sino también en

\footnotetext{
${ }^{8}$ Véase la valiosa y actual interpretación que sobre la figura de Ørsted como jurista ofrece: SERPE, A., Il pensiero filosofico e giuridico danese. Tra comunità, democrazia e diritto, Turín, G. Giappichelli Editore, 2020, en especial pp. 3-58.

9 Un muy sintético recorrido en castellano sobre el particular en: ELÍAS DE TEJADA, F., "La filosofía jurídica en la Noruega contemporánea", Revista General de Legislación y Jurisprudencia, año CII, segunda época, tomo XXIX (número 197 de la colección), septiembre de 1954, pp. 233-252.

${ }^{10}$ Ver: BLANDHOL, S., "Rettspragmatismen i Fredrik Stangs, Ragnar Knophs og Gunnar Astrup Hoels forfatterskap", Tidsskrift for Rettsvitenskap, núm. 117 (01-02), 2004, pp. 1-19.

${ }^{11}$ Sobre el particular: VICENTE Y GUERRERO, G., "Nacimiento y primeros pasos de la Sociología del Derecho en Noruega. Vilhelm Aubert y el Grupo de Oslo", Cuadernos Electrónicos de Filosofía del Derecho, número 32, 2015, pp. 111-132, en especial pp. $122-129$.

12 Véase, por todos: FURE, Eli, Eidsvoll 1814. Hvordan grunnloven ble til (Eidsvoll 1814. Cómo la Constitución llegó a ser), Oslo, Dreyers, 2013.

${ }^{13}$ Un reciente análisis en castellano sobre dicho proceso en: VICENTE Y GUERRERO, G., Constitución y revolución en los inicios del Estado nacional noruego, Madrid, Centro de Estudios Politicos y Constitucionales, 2021.
} 
el instrumento idóneo para llevar a la práctica los anhelos noruegos en busca de la consolidación tanto de un nuevo sistema liberal y parlamentario como de su propia identidad nacional ${ }^{14}$.

Es en este contexto de profundos cambios políticos y de intensa afirmación de nuevas señas identitarias nacionales en el que creció Anton Martin Schweigaard ${ }^{15}$. Su nacimiento tuvo lugar el 11 de abril de 1808 en Kragerø, pequeña localidad situada en la provincia de Telemark, en el seno de una familia de comerciantes. A lo largo de su difícil infancia, marcada por la prematura muerte de sus padres cuando apenas contaba con diez años, el pequeño Schweigaard destacó por su capacidad y esfuerzo y "det gikk over all forventning” (superó todas las expectativas) ${ }^{16}$. Tras estudiar gramática, dialéctica y retórica clásica en la Escuela de Latinidad de Skien ingresó en la Universidad de Cristianía.

En la Facultad de Derecho tuvo que estudiar profusamente la obra de Anders Sandøe Ørsted, en especial sus dos grandes trabajos: su omnipresente Haandbog over den danske og norske lovkyndighed (Manual sobre jurisprudencia danesa y noruega) ${ }^{17}$, cuyo primer volumen aparecía íntegramente dedicado a cuestiones relacionadas con la Filosofía del Derecho, y su igualmente famosa Eunomía, que reunía en cuatro volúmenes un compendio de disertaciones de Filosofía jurídica, política y moral ${ }^{18}$.

El joven Schweigaard consiguió forjarse una sólida formación académica pues, como afirma Alessandro Serpe, fue un "excelente estudiante de leyes y un atento lector de Cicerón, Quintiliano, Adam Smith, Friedrich Eduard Beneke, además de naturalmente Ørsted"19. Jens Arup Seip le incluye dentro del grupo que denominó “intelligensen" (la inteligencia), en el que se reunieron alrededor de la Universidad de Cristianía juristas y políticos como Frederik Stang o Bernhard Dunker, historiadores

14 Ver: FRYDENLUND, B., Spillet om Norge. Det politiske aret 1814 (El juego sobre Noruega. El año político de 1814), Oslo, Gyldendal, 2014.

${ }^{15}$ Sobre el "primer Schweigaard" resulta de especial interés: AUBERT, L. M. B., Schweigaards barndom og ungdom 1808-1835. Breve og erindringer (Infancia y juventud de Anton Martin Schweigaard 1808-1835. Cartas y recuerdos), Cristianía, Mallings boghandels forlag, 1883, en particular pp. XI-XC.

16 BLANDHOL, S., "Schweigaards overdrivelser" (Las exageraciones de Schweigaard), en: MESTAD, O (ed.), Anton Martin Schweigaard. Professorpolitikeren (Anton Martin Schweigaard. Profesor de políticos), Oslo, Akademisk publisering, 2009, pp. 205-227, la cita en p. 227.

17 ØRSTED, A. S., Haandbog over den danske og norske Lovkyndighed (Manual sobre jurisprudencia danesa y noruega), 6 vols., Copenhague, A. Soldin, 1822-1835.

18 ØRSTED, A. S., Eunomia: eller samling af afhandlinger, henhørende til Moralphilosophien, Stasphilosophien, og den Dansk-Norske Lovkyndighed, (Eunomía: o colección de disertaciones, relacionadas con la Filosofía Moral, con la Filosofía del Estado y con la Jurisprudencia danesa y noruega), 4 vols., Copenhague, Andreas Seidelin, 1815-1822.

19 SERPE, A., Realismo nordico e diritti umani. Le "avventure" del realismo nella cultura filosofico-giuridica norvegese, Nápoles, Editoriale Scientifica, 2008, p. 56. La traducción al castellano de los textos originales italianos de Alessandro Serpe es de mi autoría. 
como P. A. Munch o poetas y literatos como Johan Sebastian Welhaven o Henrik Wergeland ${ }^{20}$.

Tras graduarse en 1832 solicitó y obtuvo una beca del Gobierno noruego para ampliar sus estudios en el extranjero, con el objetivo de conocer de primera mano las diversas corrientes y propuestas jurídicas, filosóficas y literarias que circulaban por aquella época en la Europa continental ${ }^{21}$. Dicho viaje de estudios resultó absolutamente fundamental para terminar de moldear su formación intelectual, marcando de forma indeleble ya toda su trayectoria posterior. Se trata indudablemente del suceso que más intensamente condicionó su biografía intelectual ${ }^{22}$. Durante casi dos años recorrió Suecia, Alemania y Francia, visitando sus principales universidades.

En el verano de 1833 inició el viaje visitando las aulas de la Universidad de Lund. A continuación se trasladó a Alemania, visitando la vieja y reconocida Universidad de Greifswald. A finales de noviembre llegó a Berlín, en donde permanecería hasta finales de abril de 1834. Especial interés reviste esta larga estancia de algo más de cinco meses en su prestigiosa Universidad. Schweigaard visitó asiduamente las aulas de la Facultad de Derecho, dirigida ese curso académico por el propio Savigny, en la que se concentraban maestros como el historiador del Derecho Carl Gustav Homeyer o el filósofo del Derecho Clemens August Karl Klenze. También las aulas de la Facultad de Filosofía, en donde el influjo de Hegel, quien había fallecido a finales de 1831, se hacía notar en la mayor parte del claustro, en el que destacaba la presencia del filósofo idealista Leopold von Henning. También del historiador de la Filosofía Eduard Gans, fundador de la Escuela Filosófica del Derecho, quien despertó sobre el joven Schweigaard una curiosa antipatía.

Especial relación mantuvo Schweigaard con otro de sus profesores: el filósofo postkantiano y psicólogo Friedrich Eduard Beneke. Profundamente influido por el empirismo británico, y en especial por las ideas de John Locke, Beneke le transmitió toda su aversión y hostilidad hacia las construcciones metafísicas en general y, muy en particular, hacia la Filosofía idealista hegeliana. Para Beneke no existían verdades universalmente válidas. Los juicios eran meras fórmulas universalmente válidas sólo

\footnotetext{
${ }^{20}$ Todos ellos nacidos en una estrecha franja temporal que iría de 1807 a 1810 . Véase: SEIP, J. A., Utsikt over Norges historie, vol. I: Tidsrommet 1814 - ca. 1860 (Panorama sobre la historia noruega, vol. I: El lapso de tiempo desde 1814 hasta alrededor de 1860), Oslo, Glydendal Norsk Forlag, 2010, en especial pp. 98-103.

${ }^{21}$ Sobre dicho viaje de estudios: AUBERT, L. M. B., Schweigaards barndom og ungdom..., op. cit., en especial pp. LXXVII-LXXIX (de la introducción biográfica) y pp. 113-168 (del compendio documental).

22 Ver: AALL, A., Det historiske og litteraere grundlag for filosofien hos Anton Martin Schweigaard (Condiciones históricas y literarias para la filosofía en Anton Martin Schweigaard), I Kommission hos Cristianía, Jacob Dybwad, 1917.
} 
como fórmulas, pues con respecto a su contenido nadie podía garantizar su verdad ni su carácter absoluto. Beneke rechazaba frontalmente cualquier lógica que se pretendiera absoluta ${ }^{23}$.

Todavía en Berlín Schweigaard elaboró un notable trabajo que, posiblemente a instancias del jurista y político danés Orla Lehmann, con el que igualmente había desarrollado una buena amistad ${ }^{24}$, encontró acomodo en la revista Juridisk Tidsskrift, principal publicación jurídica danesa, hasta unos pocos años atrás dirigida por el propio Ørsted. En dicho trabajo recogía toda una serie de reflexiones personales sobre el estado de la Ciencia jurídica en Alemania. Redactado en danés con el expresivo título de "Betragtninger over Retsvidenkabens nærværende tilstand i Tydskland" (Consideraciones sobre la situación actual de la Ciencia del Derecho en Alemania) ${ }^{25}$, se adentraba con fuerza en los vericuetos caminos de la metodología jurídica, abogando especialmente por la emancipación de la Ciencia del Derecho con respecto a la Filosofía.

En su artículo Schweigaard se autodeclaraba enemigo radical del método utilizado por la Ciencia jurídica alemana, heredado del empleado por las doctrinas del Derecho natural, por la vieja escolástica e incluso por el Derecho romano. También se mostró contrario al método llevado a cabo por la Escuela Histórica del Derecho ${ }^{26}$. Afirma Fredrik Stang que tanto frente el Derecho natural como ante la Escuela de Savigny el joven noruego "stillet sig kamplysten og polemisk" (adoptó una posición belicosa y polémica $)^{27}$. La principal crítica que denunciaba Schweigaard hacía referencia a la falta de una verdadera conexión entre el mundo del Derecho y la realidad misma, por el empeño del método alemán en intentar reducir la realidad jurídica a fórmulas abstractas, lo que a su juicio producía una falsa relación entre ambos mundos, como "falskt Forhold imellem Original og Billed" (la falsa relación entre un original y la imagen $)^{28}$.

Schweigaard estuvo en Berlín todo el semestre de invierno, hasta finales de abril de 1834. Desde

\footnotetext{
${ }^{23}$ Véase: KÖHNKE, K. C., The rise of neo-kantianism, Cambridge University Press, Cambridge, 1991, en especial pp. 46 y ss.

${ }^{24}$ En este sentido: AUBERT, L. M. B., Schweigaards barndom og ungdom 1808-1835. Breve og erindringer, op. cit., p. LXXX.

${ }^{25}$ SCHWEIGAARD, A. M., "Betragtninger over Retsvidenkabens nærværende tilstand i Tyskland" (Consideraciones sobre la situación actual de la Ciencia del Derecho en Alemania), Juridisk Tidsskrift, vol. 23, 1834, pp. 292-333.

${ }^{26}$ Véase sobre el particular: DAHL, F., "Nordische Stimmen über Savigny und Gans" (Voces nórdicas sobre Savigny y Gans), Zeitschrift der Savigny-Stiftung Rechtsgeschichte, vol. 37, 1916, pp. 511-518, en especial pp. 516-518.

27 STANG, F., "Retsvidenskapen" (Ciencia del Derecho), en: Universitetet $i$ Oslo, Festskrift (Universidad de Oslo, escritos conmemorativos), Oslo, Universitetsforlaget, 1911, pp. 65-122, la cita en p. 95.

${ }^{28}$ SCHWEIGAARD, A. M., "Betragtninger over Retsvidenkabens...”, op. cit., p. 293.
} 
allí pasó a La Haya, Leipzig, Dresde, Viena, Munich y el Tirol, llegando a París en agosto de 1834 a través de Suiza sobre el llamado lago Lemán (en Ginebra). En la capital de Francia el joven noruego dedicó su tiempo principalmente a visitar los tribunales de justicia franceses, para obtener una visión práctica lo más cercana posible a la realidad de la aplicación del Código civil napoleónico y del resto de la legislación francesa.

En París permaneció hasta diciembre de ese año 1834, preparando dos interesantes trabajos. El primero de ellos fue publicado en francés con el título de "De l'état civil des femmes selon le droit de la Norvège et du Danemark" ${ }^{29}$. El mencionado artículo sentiría el calor de la imprenta a comienzos de 1835 en la Revue étrangèr de legislation et d'économie politique. El segundo fue publicado también en francés en 1835 en La France Littéraire como "De la Philosophie Allemande"30, no siendo sin embargo traducido al noruego hasta años después por el filósofo Arne Løchen con el título de "Om den tyske Filosofi”. Este trabajo va a ser objeto de atención preferente a lo largo del presente artículo.

En enero de 1835 Schweigaard visitó Copenhague, poniendo definitivamente fin a su viaje de estudios en mayo regresando a Cristianía. En la capital de Noruega se estableció y, el mismo año 1835 , contrajo matrimonio con la joven Caroline Magnin Homann, fruto del cual nacería su hijo Christian Homann Schweigaard, quien con el tiempo llegaría a ser primer ministro de Noruega. También obtuvo inmediatamente plaza de profesor en la Facultad de Derecho de Cristianía, en cuyo claustro permaneció el resto de su vida, especializándose en la enseñanza tanto de la "Statsøkonomi” (Economía política) como del "Romersk rett" (Derecho romano) ${ }^{31}$. Este hecho resulta curioso, considerando sus anteriores ataques a la influencia romanista sobre las concepciones jurídicas modernas ${ }^{32}$. Tal vez por ello sus lecciones de Derecho romano "med ryggen mot Europa” (fueron de espaldas a Europa) 33, basándose en

${ }^{29}$ SCHWEIGAARD, A. M., "De 1'état civil des femmes selon le droit de la Norvège et du Danemark", Revue étrangèr de legislation et d'économie politique, vol. II, 2, 1835, pp. 193-205.

${ }^{30}$ SCHWEIGAARD, A. M., “De la Philosophie Allemande”, La France Littéraire, año IV, 1835, vol. 17, pp. 49-106.

${ }^{31}$ Sobre la actividad docente universitaria de Schweigaard: HALVORSEN, M., "«Folk vil undervises og oplyses». A. M. Schweigaard som lærer i juridiske fag" ("El pueblo será enseñado e informado"'. A. M. Schweigaard como profesor en ciencias jurídicas), en: MESTAD, O (ed.), Anton Martin Schweigaard. Professorpolitikeren, op. cit., pp. 175-203.

32 Dag Michalsen califica esta situación "som paradoksalt" (como paradójica). MICHALSEN, D., "Romerrettsideologien i norsk rettsvitenskap" (La ideología del Derecho romano en la Ciencia del Derecho noruega), Nytt Norsk Tidskrift, 2000, pp. 414-426, la cita en p. 417.

${ }^{33}$ MICHALSEN, D., "Schweigaards romerske rett og den europeiske rettsvitenskap paa universitet og storting" (El Derecho romano de Schweigaard y la Ciencia del Derecho europea en la universidad y en el parlamento), en: MESTAD, O (ed.), Anton Martin Schweigaard. Professorpolitikeren, op. cit., pp. 335-370, la cita en p. 354. 
las Lehrbuch des heutigen Römischen Rechts del profesor alemán Ferdinand Mackeldey, autor alejado del programa de la Escuela Histórica de Savigny ${ }^{34}$.

Anton Martin Schweigaard entró a colaborar en el periódico Den Constitutionelle ${ }^{35}$, trabajando cuestiones relacionadas con Economía Política ${ }^{36}$ tras una inicial recensión sobre la Logik del filósofo danés William Sverdrup ${ }^{37}$. Dicha recensión no solo "skulle bli Schweigaards siste ord om filosofien" (se convirtió en las últimas palabras de Schweigaard sobre Filosofía) ${ }^{38}$, sino que marca, a mi juicio, la línea de cesura que permite separar al primer Schweigaard, especialmente preocupado por cuestiones relacionadas con la Filosofía, del Schweigaard político y reformador que, a partir de la década de los cuarenta, y desde su doble atalaya académica y parlamentaria, se convertiría en figura principal de la vida pública noruega ${ }^{39}$. En un personaje que, hijo de su tiempo, gustó de considerarse a sí mismo como un "kjempende tjener for sitt folk" (servidor luchando para los intereses de su pueblo) ${ }^{40}$.

\section{3. "Om den tyske Filosofi" ("Sobre la Filosofía alemana")}

\section{1. Planteamientos generales}

Si Anton Martin Schweigaard elaboró a lo largo de los primeros meses de 1834, coincidiendo con su estancia de estudios en Berlín, sus ya citadas "Betragtninger over Retsvidenkabens nærværende tilstand i Tydskland", unos pocos meses más tarde, durante su residencia en París, redactó un nuevo ensayo, esta vez en francés, que fue editado originariamente en la revista La France Littéraire con el

\footnotetext{
34 Michalsen ha sometido a examen el texto de Schweigaard en relación con el manual de Mackeldey. MICHALSEN, D., Romerrettsideologi, Oslo, Pax Forlag, 2008, en especial capítulos V y VI.

${ }^{35}$ Sobre el particular: HUSBY, E., Den Constitutionelle: et dagblad for hundre aar siden (Den Constitutionelle: un periódico de hace cien años), Oslo, 1943.

${ }^{36}$ Una aproximación a las ideas políticas y económicas de Schweigaard en: SØRENSEN, Ø., Anton Martin Schweigaards politiske tenkning (El pensamiento político de Anton Martin Schweigaard), Oslo, Universitetsforlaget, 1988.

37 SCHWEIGAARD, A. M., "Logik af William Sverdrup" (Lógica de William Sverdrup), Den Constitutionelle, núms. 17, 18 y 19, Cristianía, 17, 18 y 19 de febrero de 1836.

38 RØRVIK, T. I., "Schweigaard og Filosofien” (Schweigaard y la Filosofía), en: MESTAD, O (ed.), Anton Martin Schweigaard. Professorpolitikeren, op. cit., pp. 61-88, la cita en p. 85.

${ }^{39}$ Ver sobre el particular: HERTZBERG, E., Professor Schweigaard i hans offentlige Virksomhed 1832-1870 (El profesor Schweigaard en su actividad pública), Cristianía, Cammermeyer, 1883.

${ }^{40}$ BLANDHOL, S., Nordisk rettspragmatisme: Savigny, Ørsted og Schweigaard om vitenskap og metode (Pragmatismo jurídico noruego: sobre la ciencia y el método en Savigny, Ørsted y Schweigaard), Copenhague, DJØF Publishing, 2005, p. 216.
} 
inequívoco título "De la Philosophie Allemande"41.

Sin embargo, su versión al idioma noruego tuvo que esperar casi tres cuartos de siglo, concretamente hasta 1904, año en el que el filósofo Arne Løchen procedió a su traducción con vistas a su inmediata publicación en una edición coordinada por el economista Oskar Jaeger y por el jurista Fredrik Stang que, con el título de Ungdomsarbeider, recogía los más interesantes trabajos de juventud de Schweigaard. Su ensayo sobre la Filosofía alemana fue traducido textualmente como "Om den tyske Filosofi”, alcanzando una enorme difusión en el universo jurídico escandinavo ${ }^{42}$.

Dicho ensayo, formado por 63 páginas en su versión noruega y por 57 en el original francés, es un trabajo de indudable interés. Hay que resaltar que su principal objetivo consistió en intentar desacreditar la abstracción como medio de alcance de la verdad objetiva, atacando especialmente el método del idealismo patrocinado por Hegel, cuya Filosofía se imponía en aquellos momentos sobre cualquier otra tendencia de pensamiento en Alemania. Una de las grandes luchas que precisamente Schweigaard mantendría a lo largo de toda su trayectoria académica posterior iría encaminada a intentar evitar el triunfo del hegelianismo en Noruega ${ }^{43}$, corriente que aparecería personificada en su Universidad por el lóngevo catedrático de Filosofía teórica Marcus Jacob Monrad ${ }^{44}$.

Aunque el trabajo es notable, ello no resulta óbice para señalar ciertas deficiencias que parece necesario subrayar. En primer lugar, carencias estilísticas y de vocabulario, pues el ir dirigido al público francés condicionó desgraciadamente el tono discursivo de todo el trabajo, que en no pocas ocasiones parece demasiado monocorde y lineal, posiblemente por la falta de dominio del idioma francés por parte de su autor. En segundo lugar, ingenuidades conceptuales, ofreciendo una imagen simplistamente unilateral tanto de la Filosofía idealista en general como de la hegeliana en particular. No hay que olvidar, en este sentido, que Schweigaard escribió esta obra durante su período de

\footnotetext{
${ }^{41}$ SCHWEIGAARD, A. M., “De la Philosophie Allemande”, La France Littéraire, año IV, 1835, vol. 17, pp. 49-106.

42 SCHWEIGAARD, A. M., "Om den tyske Filosofi”" (Sobre la Filosofía alemana), en: SCHWEIGAARD, A. M., Ungdomsarbeider (Trabajos de juventud), H. Aschehoug \& Co (W. Nygaard), Cristianía, 1904. Traducción de Arne Løchen. Edición de Oskar Jaeger y Fredrik Stang, pp. 237-300.

43 Sobre la introducción y evolución histórica de la Filosofía de Hegel en Noruega, resulta imprescindible: KOPPANG, O., Hegelianismen i Norge. En idéhistorisk undersoekelse (Hegelianismo en Noruega. Una investigación sobre historia de las ideas), Oslo, Aschehoug, 1943.

${ }^{44}$ Ver sobre el particular: CHRISTOPHERSEN, H. O., Marcus Jacob Monrad: et blad av norsk dannelses historie $i$ det 19 arhundre (Jacob Monrad: una hoja en la historia de la formación de Noruega durante el siglo XIX), Oslo, Gyldendal, 1959.
} 
formación, cuando tan solo contaba con veintisiete años. Schweigaard no era un filósofo, lo que acabó convirtiéndose en una carga excesivamente pesada para quien pretendía atacar las bases metodológicas de la Filosofía hegeliana. En tercer lugar, como ocurrió en su artículo anterior sobre la Ciencia del Derecho alemana, la adopción de un tono excesivamente violento, explicable sin duda por su más que palpable fogosidad juvenil.

Pero dicha vehemencia juvenil hizo flaco favor a Schweigaard, quien en algunos pasajes de su escrito parece identificar a todas las corrientes idealistas germanas como un todo indivisible, cuyas doctrinas en ciertos momentos parecen ser objeto de un reduccionismo nada científico. Jørgen A. Stubberud señala a este respecto que el estilo de Schweigaard fue demasiado polémico y poco argumentativo, y su interpretación de las posiciones de los autores "er grovkornet og gjennomgående lite troverdig" (es tosca y generalmente poco verosímil) ${ }^{45}$.

La obra se escribió en París entre los meses de julio y diciembre de 1834, tras observar la notable influencia que sobre el universo filosófico francés empezaba a ejercer el idealismo alemán. El noruego quería avisar de los peligros de la Filosofía alemana, que a su juicio se había ido introduciendo tanto por el gusto de los franceses hacia las nuevas ideas como por la fuerza magnética que desprendía. El escrito se inicia significativamente interrogando: "Er den Bevægelse henimod den tyske Filosofi, som man paastar skal vise sig i Frankrige, bare tom Nysgjerrighed, eller har den sin Grund i en mere dybtgaaende Interesse?” (¿Es simple y vana curiosidad la que dirige al nuevo movimiento filosófico francés hacia la Filosofía alemana o es un interés más profundo? $)^{46}$.

\section{2. Un guante contra la Filosofía germana}

En "Om den tyske Filosofi" nada hay de abstracción o especulación, sino todo lo contrario, pues su objeto fundamental consistía en desenmascarar el método idealista predominante en Alemania, poniendo así en evidencia sus carencias: "Jeg har foresat mig... den tyske Methodes radikale falskhed" (yo me propongo demostrar... la radical falsedad del método alemán) ${ }^{47}$. Para ello Schweigaard no tuvo

${ }^{45}$ STUBBERUD, J. A., "En natidslesning av Schweigaards artikkel om den Tyske Rettsvidenskapen" (Una lectura actual del artículo de Schweigaard sobre la Ciencia del Derecho alemana), en: MESTAD, O (ed.), Anton Martin Schweigaard. Professorpolitikeren, op. cit., pp. 91-123, la cita en p. 112.

${ }^{46}$ SCHWEIGAARD, A. M., “Om den tyske Filosofi”, op. cit., p. 239.

${ }^{47}$ SCHWEIGAARD, A. M., “Om den tyske Filosofi”, op. cit., p. 289. 
reparo en seguir las pautas marcadas por Anders Sandøe Ørsted y por Friedrich Eduard Beneke, manteniendo e incluso intensificando sus ataques contra la sistemática empleada por el idealismo, corriente a la que consideraba cargada de abstracción, para así liberar al pensamiento jurídico de dichas cargas y poder orientar a la Ciencia Jurídica hacia el campo de las ciencias sociales.

Schweigaard intentó refutar las certezas manifestadas por la Filosofía alemana en favor de la especulación como medio para alcanzar la verdad objetiva. A su juicio "er Spekulationen, den eneste mulige Maade at filosofere paa tysk Maner" (es la especulación el único método posible para los filósofos alemanes) ${ }^{48}$. Pero en su opinión se trataba de un método "smagløst og stødende" (insípido y estancado ${ }^{49}$, que en Alemania había invadido no sólo la Filosofía sino también gran parte del resto de la literatura científica ${ }^{50}$. Para captar la atención, este método ofrecía grandes promesas y generaba grandes esperanzas, hasta el punto de que "Alle tyske Filosofer ere nemlig enige deri, at man ved den rene Spekulation kan frembringe den objektive Sandhed" (todos los filósofos alemanes están de acuerdo, en que por la pura especulación puede generarse la verdad objetiva"51.

La abstracción se convirtió en especial objeto de crítica para el jurista noruego, quien con respecto a las reglas procedentes de la escolástica y de Wolf subrayaba que "Intet skulde være mere smagløst og latterligt end denne fordringsfulde Ordflom, disse pedantiske Omveie... denne ensformige Række af syllogistiske, scholastisk regelmæssige Bevis “" (nada más insípido y ridículo que esa pretenciosa verbosidad, esos desvíos pedantes... esa monotonía de demostraciones silogísticas escolásticamente regulares $)^{52}$.

Precisamente Schweigaard afirmará que las palabras no son sino meros instrumentos prácticos para designar gran cantidad de relaciones y objetos, pero que no se deben confundir con la verdadera realidad de las cosas que representan. Por ello acusará a Hegel de haber deteriorado gravemente la naturaleza, al encuadrarla en abstracciones pálidas y defectuosas. Para Schweigaard, el maestro alemán “snur op og ned paa den naturlige Orden, idet han korrigerer Gjenstanden efter Billedet istedetfor at

\footnotetext{
${ }^{48}$ SCHWEIGAARD, A. M., “Om den tyske Filosofi”, op. cit., p. 244.

49 SCHWEIGAARD, A. M., “Om den tyske Filosofi”, op. cit., p. 247.

${ }^{50}$ SCHWEIGAARD, A. M., “Om den tyske Filosofi”, op. cit., p. 247.

${ }^{51}$ SCHWEIGAARD, A. M., “Om den tyske Filosofi”, op. cit., p. 245.

${ }^{52}$ SCHWEIGAARD, A. M., “Om den tyske Filosofi”, op. cit., p. 262.
} 
rette Kopien efter Originalen“ (invierte el orden natural de las cosas, corrigiendo el objeto según la imagen en vez de rectificar la copia según el original $)^{53}$. En este mismo sentido, el noruego señalará que los conceptos eran "forelopige Ledetraade" (hilos conductores provisionales) en la búsqueda del conocimiento objetivo, que dichos conceptos no dejaban de ser meros "stottepunkter for Erkjendelsen" (puntos de apoyo para el conocimiento).

Sin embargo, Schweigaard asegura que los filósofos alemanes son cautivos de su propio método, y que se pierden en juegos de palabras insustanciales, hablando de conceptos, de ideas y de esencias absolutas, dotando a todos sus razonamientos de un pretendido envoltorio místico con el que creen llegar a alcanzar el conocimiento y la verdad. En contraposición el verdadero sabio debe precisamente evitar, en opinión del joven noruego, caer en las atractivas trampas de los filósofos alemanes, "som ingen Forklædning, ingen sofistisk Omskrivning kan skjule” (que ningún disfraz, ninguna sofisticada perífrasis puede ocultar $)^{54}$.

Lo cierto es que, a lo largo de todo su escrito, Schweigaard ataca sin el menor rubor a los grandes pensadores germanos: a Kant, a Fichte, a Schelling y, especialmente, a Hegel. Como afirmó luminosamente el jurista y profesor de la Universidad de Copenhague Frantz Dahl (1869-1937), el joven y orgulloso Schweigaard "wirft er der deutschen Philosophie den Handschun hin” (lanzó su guante sobre la Filosofía alemana) ${ }^{55}$. Un guante en señal de reto, en especial contra el método seguido por las corrientes idealistas que marcaban el rumbo de la Filosofía en Alemania.

$\mathrm{Y}$ es que para Schweigaard el sistema hegeliano impresiona, pero no convence. La dialéctica hegeliana es un paradigmático ejemplo de desesperada contorsión del lenguaje. En dicho sistema prevalece sobre todo la jerarquía del espíritu, que es quien construye la realidad, poniendo la idea siempre por delante de la realidad, que acaba de este modo identificándose con el pensamiento. Señala el noruego que el verdadero objetivo de todo el sistema alemán es el de "sætte sine Ideer i Virkelighedens Sted" (sustituir la realidad por las ideas) ${ }^{56}$.

\footnotetext{
${ }^{53}$ SCHWEIGAARD, A. M., “Om den tyske Filosofi”, op. cit., p. 268.

${ }^{54}$ SCHWEIGAARD, A. M., “Om den tyske Filosofi”, op. cit., p. 252.

${ }^{55}$ DAHL, F., "Nordische Stimmen über Savigny und Gans”, op. cit., p. 517.

${ }^{56}$ SCHWEIGAARD, A. M., “Om den tyske Filosofi”, op. cit., p. 242.
} 
Así, desde Kant hasta Hegel, hay en su opinión un punto común en toda la Filosofía alemana, que es la arbitrariedad. Para Schweigaard "det Vilkaarlige, er Aandens Anarki" (la arbitrariedad, es la anarquía del espíritu $)^{57}$, convirtiéndose a su juicio en uno de los principales elementos que desacreditan a la Filosofía alemana. A través de juicios arbitrarios se pretende crear la realidad, no conocerla, sustituyéndola por las ideas, vicio generalizado en la Filosofía germana que se encuentra también en su misma Ciencia del Derecho.

En su opinión, las teorías de Hegel enmarcaban la realidad en un cuadro defectuoso e incoloro, en el que los conceptos se convertían en las adaptaciones de lo que los seres humanos experimentaban como realidad. Para Schweigaard resultaba indudable que "tilintetgjør Hegel Virkeligheden som individuel; han lemlæster Naturen" (Hegel destruyó la realidad individual; mutiló la naturaleza) ${ }^{58}$.

A su juicio, las tesis de Hegel hipnotizan la mente de los hombres al pretender garantizar la verdad absoluta, pues una extraña fuerza magnética parece acompañar sus vanas promesas. "Den tyske Filosofi er en Illusion" (la Filosofía alemana es una mera ilusión) $)^{59}$ subrayaría Schweigaard con agitado convencimiento. Si, en su opinión, el propio Kant había aceptado la imposibilidad de conocer la esencia absoluta de las cosas, "Hegel fremsatte som Udgangspunkt Existentsen af en saadan Erkjendelse" (Hegel estableció la existencia de ese conocimiento como punto de partida) ${ }^{60}$, abriendo por tanto la posibilidad a que dicho conocimiento fuera accesible al entendimiento humano. Como bien señala Alessandro Serpe, para Schweigaard "Hegel había devuelto a la vida los fantasmas que Kant había tratado de eliminar a través de la crítica de la razón humana"61.

Schweigaard acusará a Fichte de elevar a la "Intuition som universel og udelukkende Kilde for Erkjendelsen" (intuición como fuente universal y absoluta del saber) ${ }^{62}$. También a Schelling, en cuyo sistema "Identiteten af Ideerne og Gjenstanden blev dreven" (se ponen las ideas en el mismo nivel de

\footnotetext{
${ }^{57}$ SCHWEIGAARD, A. M., “Om den tyske Filosofi”, op. cit., p. 242.

${ }^{58}$ SCHWEIGAARD, A. M., “Om den tyske Filosofi”, op. cit., p. 268.

${ }^{59}$ SCHWEIGAARD, A. M., “Om den tyske Filosofi”, op. cit., p. 278.

${ }^{60}$ SCHWEIGAARD, A. M., “Om den tyske Filosofi”, op. cit., p. 267.

${ }^{61}$ SERPE, A., "Il realismo giuridico in Danimarca e Norvegia", Materiali per una storia della cultura giuridica, a. XXXVIII, núm. 1, junio 2008, pp. 63-90, la cita en p. 72.

${ }^{62}$ SCHWEIGAARD, A. M., “Om den tyske Filosofi”, op. cit., p. 254.
} 
realidad que los objetos) ${ }^{63}$. Ambos los encuadra como representantes de una Filosofía que "har foresat sig at skabe Sandheden og ikke at opdage den" (se propone crear la verdad, y no descubrirla) ${ }^{64}$.

En definitiva, el noruego era contrario a la existencia de una idea absoluta y universal, a la abstracción como instrumento para el conocimiento, a la especulación como método para generar la verdad objetiva y a la presunta identificación entre realidad y pensamiento. En un tono combativo de denuncia, no dudaría en señalar que en la escuela filosófica alemana dominaban la banalidad y la intolerancia intelectual, lo que a su juicio hacía que tanto el idealismo como la escolástica fueran incompatibles con el espíritu de una verdadera ciencia.

\section{3. La experiencia como fundamento del conocimiento}

Pero Schweigaard no se limitó en su ensayo simplemente a criticar las bases metodológicas del idealismo alemán, sino que dio un paso más para ofrecer su personal apuesta en favor de la experiencia como verdadero fundamento de todo conocimiento. De hecho, la falta de referentes empíricos en su opinión suponía para la Filosofía alemana su propio "Spire til Ødelæggelse" (germen destructivo) ${ }^{65}$. El noruego articuló sus ideas a partir de las enseñanzas de Ørsted, modeladas por el influjo recibido a lo largo de su viaje a Francia y Alemania, particularmente a través del ejercido por Eduard Beneke en Berlín.

Su apuesta por el pragmatismo resulta evidente. No obviamente como una doctrina filosófica sino como una actitud, una forma de entender y de encarar la aplicación de la teoría sobre la práctica, sobre el mundo real. En Schweigaard no se hallará un cuerpo de doctrina para fundamentar el pragmatismo como una Filosofía, pero compartirá de forma intuitiva muchas de las consideraciones que defenderán medio siglo más tarde Charles Peirce o William James, para quienes el pragmatismo fue en esencia una forma de aproximarse a las cuestiones filosóficas enfocada hacia sus consecuencias.

Tanto su especial rechazo a las posiciones formalistas como su decidida orientación empirista le aproximará de hecho al que generalmente se considera padre del pragmatismo jurídico clásico: el juez

\footnotetext{
${ }^{63}$ SCHWEIGAARD, A. M., “Om den tyske Filosofi”, op. cit., p. 264.

${ }^{64}$ SCHWEIGAARD, A. M., “Om den tyske Filosofi”, op. cit., p. 274.

${ }^{65}$ SCHWEIGAARD, A. M., “Om den tyske Filosofi”, op. cit., p. 246.
} 
Oliver Wendell Holmes ${ }^{66}$, al que sin embargo precede, como en los casos de Peirce, de James o de Dewey, en aproximadamente unos treinta años. Partiendo de la primacía de la práctica como rasgo central de su método pragmático, compartirá con Holmes su concepción del Derecho como realidad histórica, que con el tiempo va evolucionando y adaptándose a las circunstancias, rechazando su reducción a una serie de conceptos previamente delimitados. Para ambos la vida del Derecho no era lógica, no era conceptual, sino pura experiencia.

En un trabajo de gran interés, Jørgen Dalberg-Larsen ha puesto de manifiesto, a partir del estudio de los caracteres de la teoría del Derecho pragmática americana, si existe una teoría similar en la tradición nórdica ${ }^{67}$. Por su parte, Sverre Blandhol ha avanzado en esa misma línea entroncando a Schweigaard con dicha tradición, tanto por sus posiciones antiformalistas y antifundamentalistas como por su moderado escepticismo. También por su orientación empirista y consecuencialista, que evaluaba la validez de una teoría a partir del estudio de sus propias consecuencias ${ }^{68}$. Blandhol subraya que el pragmatismo de Schweigaard debe entenderse "som en plattform, en metode eller holdning, snarere enn en teori" (como una plataforma, un método o una actitud más que como una teoría) ${ }^{69}$.

Lo cierto es que ese pragmatismo moldeaba tanto su visión del mundo real como especialmente la forma de aproximarse al mismo, proporcionándole una actitud mental para valorar la teoría en función de su posible aplicabilidad práctica. Su principal aportación consistió en subrayar con gruesos trazos la importancia de la experiencia como fuente preferente para el conocimiento. Si éste se preocupa de la realidad, del mundo exterior, no puede basarse en los silogismos y reglas de la vieja escolástica, no debe estar separada de la vida real de los seres humanos y de sus acciones. Para Schweigaard la arrogancia de la especulación debía ceder por fin el paso al mundo de los hechos, pues la "gamle Metafysik var blot en Chimære, som man maatte stille i Klasse med Astrologien” (vieja metafísica no

\footnotetext{
${ }^{66}$ Una muy sugerente aproximación al pragmatismo jurídico del juez Holmes en: HAACK, S., “On legal pragmatism: where does «The path of the law» lead us?", American Journal of Jurisprudence, vol. 50 (1), 2005, pp. 71-105, en especial pp. 80 y ss. Una cabal interpretación de las propuestas de Susan Haack para la formación de un "pragmatismo jurídico neoclásico" en: ATIENZA, M., "Pragmatismo jurídico. La propuesta de Susan Haack", Estudios Filosóficos, vol. 67 (196), 2018, pp. 467-489.

${ }^{67}$ DALBERG-LARSEN, J., Pragmatisk retsteori (Teoría del Derecho pragmática), Copenhague, DJØF Publishing, 2001.

${ }^{68}$ BLANDHOL, S., Nordisk rettspragmatisme: Savigny, Ørsted og Schweigaard..., op. cit., en especial pp. 204 y $242-262$.

${ }^{69}$ BLANDHOL, S., Nordisk rettspragmatisme: Savigny, Ørsted og Schweigaard..., op. cit., p. 257.
} 
era más que una quimera que debía asimilarse a la astrología) ${ }^{70}$.

Ilusorio resultaba a su juicio intentar dotar a la "fornuft" (razón) de la capacidad suficiente para llegar al conocimiento si no había una confrontación previa con la experiencia. En este sentido, apunta el joven noruego la manifiesta imposibilidad de proceder al traslado de las reglas que rigen los mundos de la lógica y de las matemáticas para dirigir la dimensión del universo social. Este se encuentra a su juicio siempre marcado por una incertidumbre que es consustancial al propio fenómeno social y al sujeto principal de dicho fenómeno: el ser humano, cuyas relaciones son a menudo tan inciertas y volubles como poliédricas.

Con respecto al sistema jurídico, afirmaría Schweigaard que el Derecho es a la ciencia lo que la ciencia es a la sociedad, una combinación de praxis y de teoría ${ }^{71}$. Estas conexiones entre sociedad, Derecho y realidad se relacionan entre sí con el objeto de moldear las concepciones mismas de lo jurídico. En su opinión las normas jurídicas no eran abstractos oráculos divinos, sino productos incompletos de la actividad de los seres humanos, y precisamente por ello necesitaban de su constante reforma y actualización. Este carácter cambiante es consecuencia directa de la propia inestabilidad que preside las complejas relaciones humanas. Para Schweigaard la Ciencia jurídica debía tener muy en cuenta la mutabilidad de las normas, su carácter no absoluto, y dedicarse a tender puentes con la realidad, analizando las condiciones y las consencuencias sociales que se derivan de la efectiva aplicación de las normas.

El Derecho no podía caracterizarse como expresión de una lógica superior, ni de un orden metafísico previo, sino como algo provisional y rectificable, que encontraba su verdadero fundamento no en la voluntad de Dios, sino en su propia necesidad. Precisamente esta fundamentación del Derecho a partir de su "uundgaaelige Nødvendighed" (inevitable necesidad) ${ }^{72}$ constituye una idea de gran interés. Su concepción del Derecho como un "nødrettslig fenomen” (fenómeno necesario) supone sin duda una de las principales aportaciones de Schweigaard ${ }^{73}$.

\footnotetext{
${ }^{70}$ SCHWEIGAARD, A. M., “Om den tyske Filosofi”, op. cit., p. 252.

${ }^{71}$ SCHWEIGAARD, A. M., “Om den tyske Filosofi”, op. cit., pp. 272-273.

72 SCHWEIGAARD, A. M., "Betragtninger over Retsvidenkabens...”, op. cit., p. 329.

${ }^{73}$ Véase sobre el particular: STUBBERUD, J. A., "En natidslesning av Schweigaards artikkel om den Tyske Rettsvidenskapen", op. cit., en especial pp. 106-112. Ver igualmente: RØRVIK, T. I., "Schweigaard og Filosofien”, op. cit., en especial pp. 79-81.
} 
Señala Dag Michalsen que el joven jurista estableció dos importantes requisitos en su deseo de intentar orientar metodológicamente a la nueva Ciencia Jurídica noruega: en primer lugar, promover la mayor libertad posible a la hora de interpretar el Derecho. En segundo lugar, proceder a tratar las cuestiones jurídicas mediante un análisis puramente descriptivo de las mismas: "Det måtte gjores på en «analytisk deskriptiv» måte" (tenía que hacerse de forma «analítica descriptiva») ${ }^{74}$. El idealismo, con toda su carga metafísica, abstracta y especulativa, debía ceder el paso al mundo real. Se imponía por tanto una aproximación que valorara la dimensión práctica del fenómeno jurídico.

En su anterior "Betragtninger over Retsvidenkabens" Schweigaard afirmaba que, partiendo de la observación de la misma experiencia, metodológicamente cabía hablar de "fundamenter for det Bindende i Retsbudene" (fundamentos para la vinculación de los preceptos legales) ${ }^{75}$, de criterios o fuentes alternativas a la hora de proceder a considerar las cuestiones jurídicas. Tras incidir en la necesidad de tomar en consideración cada caso de forma concreta y particularizada, de abrirse a la naturaleza del caso individual, Schweigaard señalaba especialmente la equidad: "Billighed" y la utilidad: "Nytte" como dos de esos posibles fundamentos o fuentes, a los que se podía llegar de forma primaria (a través de la intuición) o secundariamente mediante una discusión racional.

En primer lugar, recogía la equidad: "Billighed”, la imparcialidad, la mesura y la prudencia: "det Billige" (lo equitativo). Schweigaard incluía en parte, dentro de la equidad, las consideraciones de justicia: "retfærdighed", pero no así las consideraciones de racionalidad, lo razonable: "det fornuftige". En segundo lugar, señalaba la utilidad: "Nytte”, lo útil: "det Nyttige”, lo que resultaba coherente con una construcción empirista en la que se daba un papel preponderante a la experiencia como fuente principal de acceso al conocimiento. No parece por ello casual, aunque en mi opinión sea exagerado, que Seip subrayara que Schweigaard fue utilitarista por encima de todo, y que desarrolló una forma casi pura de utilitarismo ${ }^{76}$.

De hecho, el joven noruego parece incidir a mi juicio en la prevalencia de una tercera fuente: "det Rette", cuya verdadera acepción debe entenderse, más que como el Derecho o la ley en términos

\footnotetext{
${ }^{74}$ MICHALSEN, D., Norsk rettstenkning etter 1800. Tolv studier (Pensamiento jurídico noruego después de 1800. Doce estudios), Oslo, Pax Forlag, 2013, p. 142.

${ }^{75}$ SCHWEIGAARD, A. M., "Betragtninger over Retsvidenkabens...,", op. cit., p. 303.

${ }^{76}$ SEIP, J. A., Utsikt over Norges historie..., op. cit., vol. I, p. 103.
} 
generales, como lo que es considerado legalmente correcto, de acuerdo con la noción de validez legal, que es lo que verdaderamente dota de existencia a la norma. Para Schweigaard constituía un error pensar que las dos fuentes anteriores pudieran competir con la validez jurídica: “det er kun ved en vilkaarlig Abstraction man kan sætte det Nyttige og det Billige mod det Rette" (es solo por una arbitraria abstracción por la que uno puede elegir lo útil o lo equitativo contra lo jurídicamente válido $)^{77}$.

Schweigaard juzgaba erróneo entender la utilidad o la equidad como fuentes alternativas de normatividad. Las normas jurídicas habían sido establecidas por alguna autoridad legal respondiendo a cuestiones jurídicas generales en base a argumentaciones que tomaban en cuenta todo tipo de consideraciones, como efectivamente podían ser la utilidad y la equidad, pero también el resto de normas jurídicas que previamente pertenecían ya al sistema jurídico. Eran precisamente esas decisiones de la autoridad legal en forma de normas las que verdaderamente debían gozar de la consideración de Derecho existente y válido, y por tanto ser la fuente a valorar en el momento de razonar y decidir sobre cuestiones jurídicas.

\section{Conclusión}

El reconocimiento del peso intelectual de la obra científica de Schweigaard en el ulterior desarrollo de la Ciencia del Derecho en Noruega resulta un tópico generalizado entre los juristas nórdicos. Dag Michalsen advierte no obstante que Schweigaard fue un auténtico símbolo para los juristas noruegos del siglo XIX, lo que sin duda "har smittet over pa oppfatningen av ham som juridisk forfatter" (ha contaminado la percepción de él como autor jurídico) ${ }^{78}$.

Fuera del ámbito escandinavo, Alessandro Serpe subraya con razón que los trabajos elaborados por el joven Schweigaard representaron "el primer manifiesto de ciencia jurídica que la literatura filosófico jurídica noruega había conocido"79. A mi juicio, en sus dos ensayos sobre la Filosofía alemana demostró una gran intuición de lo que con posterioridad se convertiría en el razonamiento jurídico moderno, lo que constituye una de esas "anticipaciones" tan buscadas entre los historiadores de

\footnotetext{
${ }^{77}$ SCHWEIGAARD, A. M., "Betragtninger over Retsvidenkabens...”, op. cit., p. 307.

${ }^{78}$ MICHALSEN, D., Norsk rettstenkning etter 1800..., op. cit., pp. 126 y 127.

${ }^{79}$ SERPE, A., Realismo nordico e diritti umani..., op. cit., p. 59.
} 
las ideas.

No obstante Schweigaard no fue ni un filósofo ni, por descontado, un filósofo del Derecho, sino un hombre de acción, un político, un reformador, que recurrió al Derecho positivo durante las décadas centrales del siglo XIX en su proyecto de modernización de las viejas estructuras políticas, económicas y sociales noruegas. Rune Slagstad subraya que participó activamente en la construcción de la joven Noruega como un "handlingsideolog" (ideólogo de acción) $)^{80}$, adoptando una posición que podría denominarse como "pragmatisk utilitarisme” (utilitarismo pragmático) ${ }^{81}$.

Y lo cierto es que desde esas posiciones pragmáticas Schweigaard criticó una forma de argumentación que operaba con modelos de lógica formal, basado en un sistema de conceptos tajantemente delimitados. La Filosofía alemana percibía los conceptos como sustancias bien determinadas, y creía que la realidad se correspondía con los límites de tales conceptos. Sin embargo, a su juicio la lógica sistemática debía dejar paso a una nueva forma de argumentación, que pudiera valorar la multiplicidad de realidades y cambios que fluían constantemente en el mundo real, marcando el devenir de los individuos en el marco de su propia vida social.

Schweigaard se preocupó por intentar acercar el Derecho a la sociedad, liberándolo de las cadenas que le ataban a un universo conceptual sin referentes reales. Y por ello sus críticas, a menudo provistas de una excesiva carga emotiva, a todas aquellas visiones que atraparan al hecho jurídico dentro de un férreo sistema lógico fueron imprescindibles tanto para el rechazo a las corrientes idealistas y iusnaturalistas como para el singular rumbo pragmático, empirista y utilitarista que marcaría ya el desarrollo futuro de la Ciencia jurídica noruega.

\footnotetext{
${ }^{80}$ SLAGSTAD, R., De nasjonale strateger (Los estrategas nacionales), Oslo, Pax Forlag, 1998.

${ }^{81}$ SLAGSTAD, R., "Tre motiver samt utilitarisme og naturrett: norsk rettstenkning fra Schweigaard til Seip" (Tres motivos sobre utilitarismo y Derecho natural: el pensamiento jurídico noruego desde Schweigaard hasta Seip), en: ID, Rettens ironi (Ironías del Derecho), Oslo, Pax Forlag, 2001, p. 67.
} 


\section{Bibliografía}

ATIENZA, M., "Pragmatismo jurídico. La propuesta de Susan Haack”, Estudios Filosóficos, vol. 67 (196), 2018, pp. 467489.

AUBERT, L. M. B., Schweigaards barndom og ungdom 1808-1835. Breve og erindringer, Cristianía, Mallings boghandels forlag, 1883.

BLANDHOL, S., "Rettspragmatismen i Fredrik Stangs, Ragnar Knophs og Gunnar Astrup Hoels forfatterskap", Tidsskrift for Rettsvitenskap, núm. 117 (01-02), 2004, pp. 1-19.

BLANDHOL, S., Nordisk rettspragmatisme: Savigny, Orsted og Schweigaard om vitenskap og metode, Copenhague, Juristog Okonomforbundets Forlag, 2005.

BLANDHOL, S., "Schweigaards overdrivelser", en: MESTAD, O (ed.), Anton Martin Schweigaards. Professorpolitikeren, Oslo, Akademisk publisering, 2009, pp. 205-227.

CHRISTOPHERSEN, H. O., Marcus Jacob Monrad: et blad av norsk dannelses historie i det 19 arhundre, Oslo, Gyldendal, 1959.

DAHL, F., "Nordische Stimmen über Savigny und Gans", Zeitschrift der Savigny-Stiftung Rechtsgeschichte, vol. 37, 1916, pp. 511-518.

DALBERG-LARSEN, J., Pragmatisk retsteori, Copenhague, DJØF Publishing, 2001.

ECKHOFF, T., Rettsvesen og Rettsvitenskap i USA, Oslo, Akademisk Forlag, 1953.

ELÍAS DE TEJADA, F., "La Filosofía jurídica en la Noruega contemporánea", Revista General de Legislación y Jurisprudencia, año CII, segunda época, tomo XXIX (número 197 de la colección), septiembre de 1954, pp. 233-252.

EVALD, Jens, Alf Ross - Et liv, Copenhague, Djøf Forlag, 2010. Traducción inglesa: Alf Ross - A life, Copenhague, Djøf Forlag, 2014.

FURE, Eli, Eidsvoll 1814. Hvordan grunnloven ble til, Dreyers, Oslo, 2013.

HAACK, S., "On legal pragmatism: where does «The path of the law» lead us?", American Journal of Jurisprudence, vol. 50 (1), 2005, pp. 71-105.

HAGERUP, F., “Nogle ord om den nyere Retsvidenskaps karakter”, Tidsskrift for Retsvidenskab, núm. 1, 1888, pp. 1-58.

HERTZBERG, E., Professor Schweigaard i hans offentlige virksomhed 1832-1870, Cristianía, Cammermeyer, 1883.

HIERRO, L., El realismo jurídico escandinavo. Una teoría empirista del Derecho, Valencia, Fernando Torres, 1981.

KOPPANG, O., Hegelianismen i Norge. En idéhistorisk undersoekelse, Oslo, Aschehoug, 1943.

KÖHNKE, K. C., The rise of neo-kantianism, Cambridge, Cambridge University Press, 1991.

MICHALSEN, D., "Romerrettsideologien i norsk rettsvitenskap”, Nytt Norsk Tidskrift, 2000, pp. 414-426.

MICHALSEN, D., Romerrettsideologi, Oslo, Pax Forlag, 2008.

MICHALSEN, D., "Schweigaards romerske rett og den europeiske rettsvitenskap paa universitet og storting", en: MESTAD, O (ed.), Anton Martin Schweigaards. Professorpolitikeren, Oslo, Akademisk publisering, 2009, pp. 335370.

MICHALSEN, D., Norsk rettstenkning etter 1800. Tolv studier, Oslo, Pax Forlag, 2013.

RØRVIK, T. I., "Schweigaard og Filosofien" en: MESTAD, O (ed.), Anton Martin Schweigaards. Professorpolitikeren, Oslo, Akademisk publisering, 2009, pp. 61-88. 
ROSS, A., Om ret og retfcerdighed, Copenhague, Nyt nordisk forlag, 1953. Traducción al castellano: Sobre el Derecho y la Justicia, Buenos Aires, Eudeba, 1963.

SCHWEIGAARD, A. M., "Betragtninger over Retsvidenkabens nærværende tilstand i Tyskland", Juridisk Tidsskrift, vol. 23, 1834, pp. 292-333.

SCHWEIGAARD, A. M., "De l'état civil des femmes selon le droit de la Norvège et du Danemark", Revue étrangèr de legislation et d'économie politique, vol. II, 2, 1835, pp. 193-205.

SCHWEIGAARD, A. M., "De la Philosophie Allemande", La France Litteraire, año IV, 1835, vol. 17, pp. 49-106. Edición en noruego: "Om den Tyske Filosofi”: en ID., Ungdomsarbeider, Cristianía, H. Aschehoug \& Co (W. Nygaard), 1904, pp. 237-300. Traducción al noruego de Arne Løchen. Edición de Oskar Jaeger y Fredrik Stang.

SCHWEIGAARD, A. M., "Logik af William Sverdrup”, Den Constitutionelle, núms. 17, 18 y 19, Cristianía, 17, 18 y 19 de febrero de 1836.

SEIP, J. A., Utsikt over Norges historie, vol. I: Tidsrommet 1814 - ca. 1860, Oslo, Glydendal Norsk Forlag, 2010.

SERPE, A., "Il realismo giuridico in Danimarca e Norvegia", Materiali per una storia della cultura giuridica, a. XXXVIII, núm. 1, junio 2008, pp. 63-90.

SERPE, A., Realismo nordico e diritti umani. Le "avventure" del realismo nella cultura filosofico-giuridica norvegese, Nápoles, Editoriale Scientifica, 2008.

SERPE, A., Il pensiero filosofico e giuridico danese. Tra comunità, democrazia e diritto, G. Turín, Giappichelli Editore, 2020.

SLAGSTAD, R., "Norsk rettsrealisme etter 1945”, Tidsskrift for Rettsvitenskap, 1987, pp. 385-403.

SLAGSTAD, R., De nasjonale strateger, Oslo, Pax Forlag, 1998.

SLAGSTAD, R., "Tre motiver samt utilitarisme og naturrett: norsk rettstenkning fra Schweigaard til Seip", en: ID., Rettens ironi, Oslo, Pax Forlag, 2001.

SØRENSEN, Ø., Anton Martin Schweigaards politiske tenkning, Oslo, Universitetsforlaget, 1988.

STANG, F., “Retsvidenskapen”, en: Universitetet i Oslo, Festskrift, Oslo, Universitetsforlaget, 1911, pp. 65-122.

STUBBERUD, J. A., "En natidslesning av Schweigaards artikkel om den Tyske Rettsvidenskapen”, en: MESTAD, O (ed.), Anton Martin Schweigaards. Professorpolitikeren, Oslo, Akademisk publisering, 2009, pp. 91-123.

VICENTE Y GUERRERO, G., "Nacimiento y primeros pasos de la Sociología del Derecho en Noruega. Vilhelm Aubert y el Grupo de Oslo", Cuadernos Electrónicos de Filosofía del Derecho, número 32, 2015, pp. 111-132.

VICENTE Y GUERRERO, G., Constitución y revolución en los inicios del Estado nacional noruego, Madrid, Centro de Estudios Políticos y Constitucionales, 2021.

AALL, A., Det historiske og litteraere grundlag for filosofien hos Anton Martin Schweigaard, Cristianía, I Kommission hos Jacob Dybwad, 1917. 